\title{
No somos delincuentes: mobilizações de moradores em um bairro cigano na Catalunha
}

No somos delincuentes: mobilizations of residents in a Romani neighborhood in Catalonia

\section{Nathalia Ferreira Gonçales}

\section{(2) OpenEdition}

Edição electrónica

URL: http://journals.openedition.org/aa/5896

DOI: 10.4000/aa.5896

ISSN: 2357-738X

\section{Editora}

Programa de Pós-Graduação em Antropologia Social (UnB)

Edição impressa

Paginação: 230-238

ISSN: 0102-4302

\section{Refêrencia eletrónica}

Nathalia Ferreira Gonçales, «No somos delincuentes: mobilizações de moradores em um bairro cigano na Catalunha», Anuário Antropológico [Online], v.45 n.2 | 2020, posto online no dia 27 maio 2020, consultado o 28 abril 2021. URL: http://journals.openedition.org/aa/5896 ; DOI: https://doi.org/ 10.4000/aa.5896

\section{(c) (i) (9)}

Anuário Antropológico is licensed under a Creative Commons Atribuição-Uso Não-Comercial-Proibição de realização de Obras Derivadas 4.0 International. 


\section{No somos delincuentes: mobilizações de moradores em um bairro cigano na Catalunha}

No somos delincuentes: mobilizations of residents in a Romani neighborhood in Catalonia

DOI: https://doi.org/10.4000/aa.5896

\section{Nathalia Ferreira Gonçales • Museu Nacional, Universidade Federal do Rio de Janeiro - Brasil}

Doutoranda no Programa de Pós-graduação em Antropologia Social do Museu Nacional da Universidade

Este ensaio apresenta as mobilizações dos moradores de Font de la Pólvora, zona leste da cidade de Girona, comunidade da Catalunha, em decorrência dos sucessivos cortes de luz que estão acontecendo há alguns anos no bairro. A institucionalização dos processos de precarização desse território, marcado desde sua constituição por narrativas de marginalização e abandono, acentua uma política de escassez histórica do Estado em torno da população residente, majoritariamente de etnia cigana. Através de atos públicos, os moradores buscam contestar o imaginário de contravenção que persiste e atualiza as inscrições de vulnerabilidade presentes no cotidiano do bairro.
This essay presents how the dwellers from Font de la Pólvora, in the east area of Girona city, in the Spanish community of Catalonia, have mobilized after successive power cuts that have been happening for some years in the neighborhood. This territory, marked from its emergence by narratives of marginalization and neglect, has been subject to increased precarity, in processes whose institutionalization accentuates a policy of historical scarcity of State presence around the local, mostly Romani population. Through public action, dwellers seek to contest the imaginary of contravention that persists and updates the inscriptions of vulnerability that are present in the neighborhood daily life. 
Este ensaio apresenta as mobilizações dos moradores de Font de la Pólvora em decorrência dos constantes cortes de luz que estão ocorrendo no bairro há alguns anos. Ruas estreitas, enormes muralhas e igrejas medievais compõem o clássico cartão-postal da cidade de Girona, situada a poucos quilômetros de Barcelona. Acompanhando o curso do mesmo rio que corta as casas coloridas do centro histórico, a paisagem vai gradualmente cedendo lugar a uma larga avenida que, combinada à modesta zona industrial da região, anuncia a dobra específica de territórios em processo contínuo de reinvenção e negociação. Font de la Pólvora, parte da zona leste de Girona, comunidade da Catalunha, é um bairro recente constituído majoritariamente por ciganos. Ali vivem cerca de 2 mil pessoas, configurando laços de famílias que se estruturam entre os apartamentos por proximidade. A organização espacial faz com que o bairro se separe do centro histórico por uma pequena montanha. Existe um único acesso através de uma ponte, o que limita radicalmente sua comunicação e integração com o resto da cidade. Nesse sentido, emerge a ideia leiga de que Font de la Pólvora constitui, simbólica e territorialmente, um gueto cujo projeto de precarização das vidas nesse marco perpassa narrativas estigmatizantes de delinquência, criminalidade e atividades feitas na chave do não-dito.

Resultado de um plano de urbanização que buscou erradicar o barraquismo ${ }^{1}$ em Girona, o bairro foi construído na década de 1970, ainda sob regime franquista, para acomodar a onda migratória que chegou sobretudo da região sul da Espanha, onde as possibilidades de trabalho eram escassas e o tamanho da miséria recordava um prolongamento assombroso dos tempos de guerra. Como sintoma de um programa de atuação típico das políticas nacionais desenvolvimentistas que caracterizam os regimes ditatoriais, a economia catalã da época foi fortemente estimulada pela crescente industrialização local, atraindo um fluxo de população que buscava na cidade alguma perspectiva de melhoria nos arranjos da vida. Ir embora significava perder um pouco de si, deixar para trás a família, a casa, o povoado de origem, levar penosamente o indispensável e partir em busca do que seria uma aposta de futuro mais próspero.

Durante os doze meses de trabalho de campo, pude acompanhar diversos protestos e suas tramas políticas em decorrência dos sucessivos cortes de luz que estão acontecendo há alguns anos no bairro. A empresa contratada pela prefeitura atribui os cortes no setor leste da cidade às fraudes elétricas engendradas pelos próprios moradores que, segundo a companhia, estabelecem conexão clandestina com o serviço disponível. Tal ação produziria uma sobrecarga na fiação elétrica, gerando pane no sistema e falta de fornecimento para os apartamentos locais. No entanto, o sistema de rede instalado data do mesmo período de construção do bairro, não tendo sofrido nenhum tipo de revisão técnica ou atualização nos seus cabos de força. Através de declarações públicas dos representantes políticos elaboradas em reuniões, assembleias e coletivas de imprensa, é flagrante a constante tentativa de criminalização do bairro em sua totalidade, como se fosse possível instituir uma dimensão existencial propensa a condutas desviantes e práticas de infração que seriam a causa última da interrupção prolongada de energia. Ao
1 Em território espanhol, o termo chabola ou barraca é utilizado com ampla frequência para fazer referência a casas precárias e autofabricadas. Desta maneira, expressões como chabolismo ou barraquismo, que contextualmente podem designar um sentido injurioso, aparecem neste ensaio ora como menção a discursos institucionais, ora como representação performativa de espaços de vulnerabilidade. 
longo dos problemas que emergem no cotidiano do bairro, estes modos de habitar a escassez vão conformando um campo de práticas e representações - presente tanto nas falas frequentes de pessoas do local como em diferentes instituições de governo - sobre inscrições de vulnerabilidade e reinvenções de possibilidades de vida às margens do Estado.

As fotografias que compõem esta publicação foram registradas durante o estágio doutoral no Departament d'Antropologia Social i Cultural da Universitat Autònoma de Barcelona com bolsa CAPES/PDSE, nos anos de 2018 e 2019. As condições de realização se deram a partir da minha inserção na recém-criada Plataforma pela Dignidade de Font de la Pólvora, associação composta por moradores e pessoas vinculadas a mobilizações sociais. Como parte do conselho administrativo encarregado pela fundação da Plataforma, participei ativamente na representação e organização das atividades desempenhadas pela entidade. Deste modo, a Plataforma emerge na intenção de marcar oposição pública às inúmeras tentativas de criminalização do bairro, sendo responsável por organizar a manifestação que vem a resultar neste ensaio visual. A função de retratar o ato partiu de um propósito coletivo do grupo na reivindicação e disputa por visibilidade a respeito das adversidades locais.

Tamanha institucionalização dos processos de precarização do bairro, marcado desde sua constituição por narrativas de marginalização e abandono, acentua uma política de escassez histórica do Estado espanhol e catalão em torno da população residente, majoritariamente de etnia cigana, e agrava o imaginário de contravenção sobre práticas e condutas inscritas naquele território. Neste sentido, as marcas de vulnerabilidade em Font de la Pólvora, materializadas pelos contínuos cortes no subministro de energia elétrica, configuram formas de violência repetidas no cotidiano do bairro. Através de mobilizações públicas, a Plataforma busca evidenciar uma gestão nefasta da empresa de energia contratada pela prefeitura da cidade. Na tentativa de contestar o caráter de gueto forjado por um modo de governança que constrói e mantém margens territoriais e corporais nas quais o próprio poder do Estado se (re)faz, os moradores levaram para as ruas de Girona cartazes com frases que ressoavam precisamente como um preâmbulo de incontáveis reparações: "nós não somos delinquentes". 


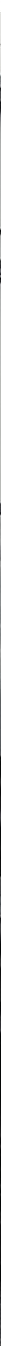

Os registros deste ensaio foram feitos no primeiro protesto organizado pela Plataforma pela Dignidade de Font de la Pólvora, associação composta por moradores e movimentos sociais com objetivo de denunciar os sucessivos cortes de luz no bairro. Em um dia de inverno, a manifestação saiu da Font de la Pólvora e avançou até a prefeitura de Girona, localizada no centro histórico da cidade. 
Nathalia Ferreira Gonçales

Fina levou para a rua sua conta de luz quitada dentro do prazo de vencimento, contrariando as sentenças culposas de empresários e políticos que responsabilizam o fracasso no fornecimento de energia à suposta fraude elétrica engendrada pelos moradores.
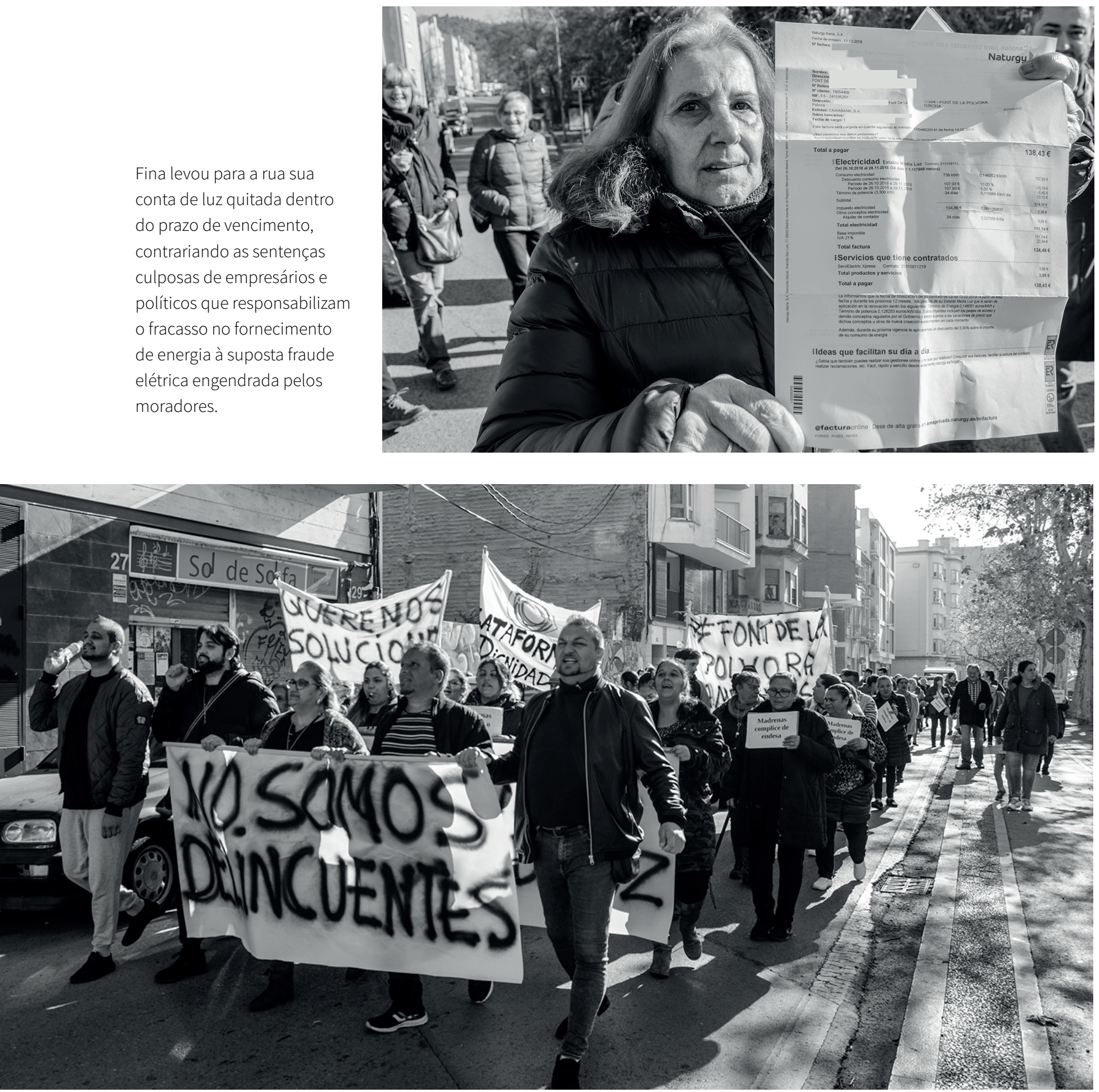

O Plano Parcial de Font de la Pólvora foi aprovado em fevereiro de 1972. No texto do projeto fazia constar a urgência que as obras requeriam, com a finalidade de conseguir a definitiva erradicação do barraquismo. Como as autoridades se encarregariam de repetir durante os anos que duraram sua construção, o bairro colocaria um fim efetivo às chabolas de Girona. Font de la Pólvora foi um território planejado para ser habitado por um excedente de migrantes, quase todos ciganos. Durante a manifestação, moradores sinalizaram com indignação as políticas assimétricas de gestão da cidade e sua população: "Nunca nos dão atenção porque somos ciganos". 


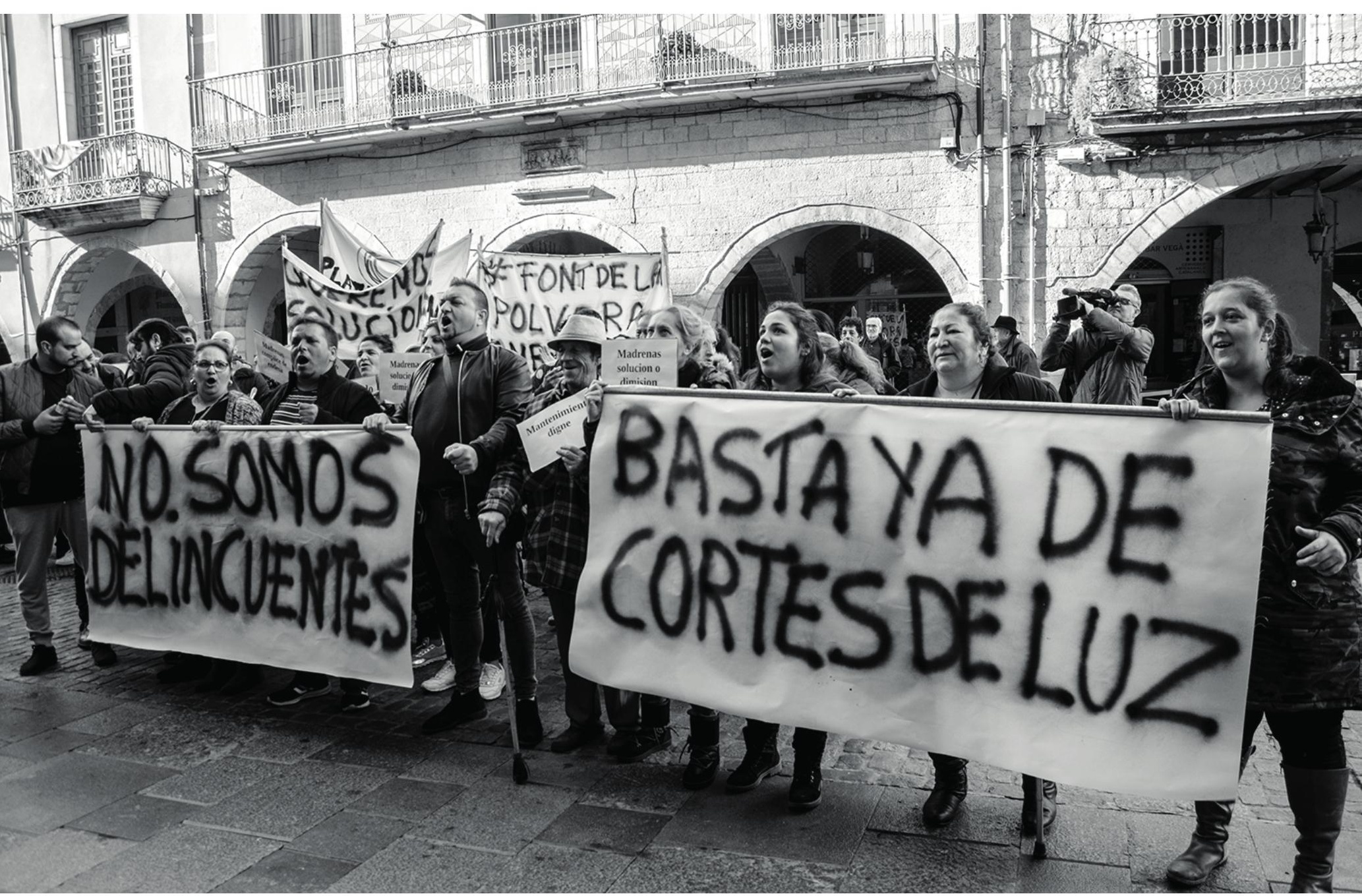

Em relação à execução dos prédios, Font de la Pólvora apresentou graves deficiências desde o início das locações. Após uma exaustiva cruzada burocrática que outorgou acesso aos apartamentos, os moradores se encontraram diante de residências de baixa qualidade. Além das reduzidas dimensões para famílias numerosas, os blocos de concreto logo apresentaram goteiras e umidade em seu interior. Igualmente houve diversas reclamações sobre problemas relacionados às precárias instalações elétricas. Nos cartazes e palavras de ordem presentes na manifestação, moradores atribuíram os cortes sofridos à antiguidade da rede e solicitaram em caráter de emergência a substituição da fiação elétrica no bairro. 


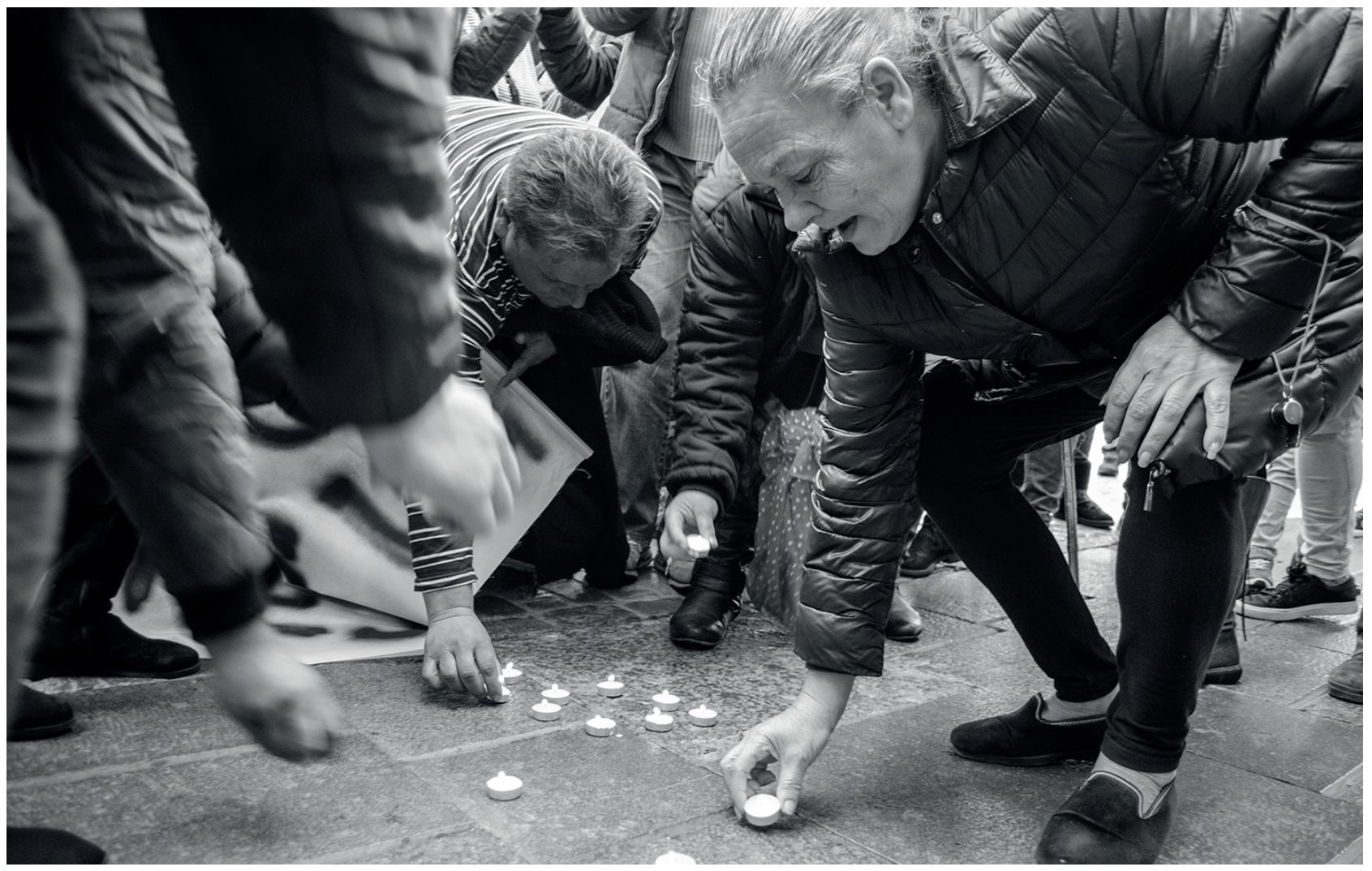

De maneira incontestável, o bairro inaugurado não dispunha de todos os benefícios previstos. O afã especulativo das grandes empreiteiras, aliado à política higienista de limpeza da cidade e contenção das massas migrantes concentradas em zonas de barracas, levantou um polígono residencial composto por apartamentos extremamente malfeitos, com escassez de serviços básicos para uma população que viria a habitar o que foi denominado em seguida como chabolismo vertical. As narrativas de marginalização e delinquência ainda persistem e atualizam os processos de precarização no bairro.

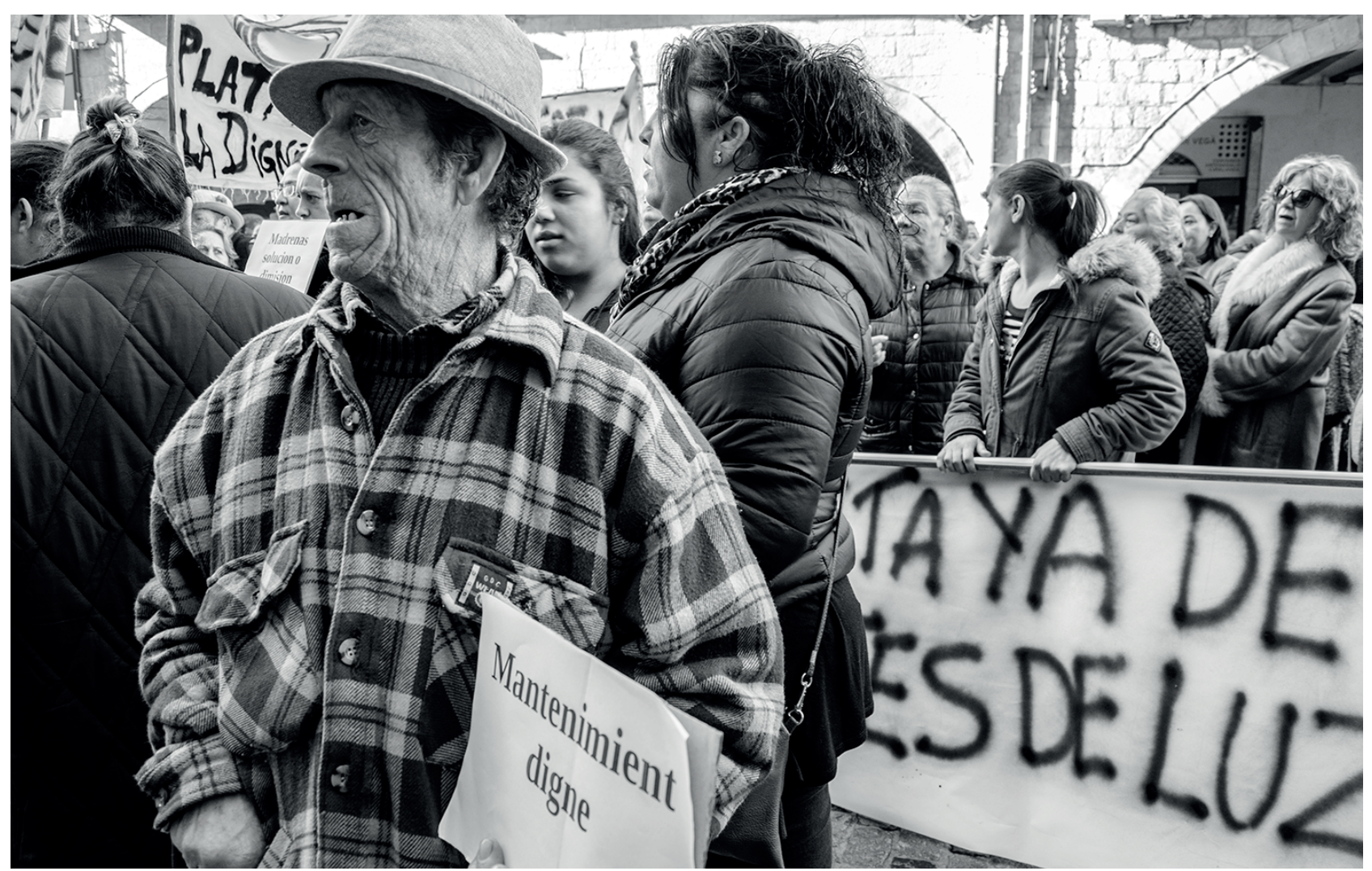


Nathalia Ferreira Gonçales

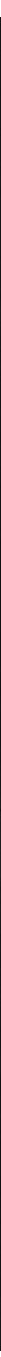

As consequências desta política de administração desastrosa, tramada na desatenção em relação a todas as transformações que acontecem no local, fortalecem ainda mais a ideia estigmatizante de que Font de la Pólvora conforma um gueto apartado do restante de Girona. $\mathrm{Na}$ intenção de marcar oposição pública às inúmeras tentativas de criminalização, os moradores seguem denunciando a empresa de energia contratada pela prefeitura da cidade. A perspectiva de protesto na forma de associações e mobilizações caminha junto com pequenas agências cotidianas elaboradas em meio aos sucessivos cortes de luz. A narrativa de vizinhas que puxam cabos de uma casa a outra durante as interrupções localizadas e, desta maneira, transferem eletricidade através de uma comunicação improvisada entre as janelas, permite elaborar outras possibilidades de habitar as tramas relacionais da vida no bairro. 